\title{
Fast building damage mapping using a single post-earthquake PoISAR image: a case study of the 2010 Yushu earthquake
}

Wei Zhai ${ }^{1,2,3}$ and Chunlin Huang ${ }^{2^{*}}$

\begin{abstract}
Earthquakes are one of the most destructive natural disasters. Efficiently and quickly acquiring building earthquake damage information can help to reduce the casualties after an earthquake. In this paper, for convenience, speed, and precision, building damage information is extracted using a single post-earthquake PoISAR image. In PolSAR images, the undamaged parallel buildings characterized by double-bounce scattering are different from the collapsed buildings characterized by volume scattering, but the undamaged oriented buildings are very similar to collapsed buildings because of their scattering mechanism ambiguity in the early traditional model-based decomposition. Therefore, the collapsed buildings are difficult to extract accurately. In this paper, the scheme of polarization orientation angle (POA) compensation is employed to enhance the double-bounce scattering power of the oriented buildings, and the difference in the relative contribution change rate of scattering components before and after POA compensation is proposed to further enhance the difference between collapsed buildings and oriented buildings, in order that the collapsed buildings can be extracted more accurately. The "4.14"Yushu earthquake, which occurred in Yushu County, Qinghai province of China, is used as the case study to test the proposed method, and an airborne high-resolution PoISAR image of the urban region of Yushu County is used in the experiment. The experimental results show that the accuracy of building damage information extraction can be improved by the use of the proposed method, compared with the traditional polarimetric classification.
\end{abstract}

Keywords: Earthquake, PoISAR, Collapsed buildings, Damage mapping, Polarization orientation angle

\section{Introduction}

Earthquakes can give rise to great damage to life and property. In an earthquake, most of the casualties are caused by collapsed buildings, so building damage information extraction is the main task of earthquake damage information investigation (Trianni and Gamba 2009). At present, remote sensing technology is widely used in the investigation of natural disasters (Zhang et al. 2001). Remote sensing images can have a wide coverage and can even cover areas that people cannot reach, and the use of remote sensing images to obtain disaster information

\footnotetext{
*Correspondence: huangcl@|zb.ac.cn

${ }^{2}$ Key Laboratory of Remote Sensing of Gansu Province, Heihe Remote Sensing Experimental Research Station, Cold and Arid Regions Environmental and Engineering Research Institute, Chinese Academy of Sciences, Lanzhou 730000, Gansu, China

Full list of author information is available at the end of the article
}

is much faster than a ground survey (Dell'Acqua et al. 2013). After an earthquake, the collapsed building information should be acquired in a timely manner and can be used to guide the effective implementation of the emergency rescue, which is crucial for the reduction in casualties (Susaki 2015). Although optical remote sensing images are intuitive and easy to understand, they are directly restricted by sunlight, and optical remote sensors cannot image the earth under cloudy, rainy, foggy, and other inclement weather (Gamba et al. 2007; de Michele et al. 2010). Radar is not affected by weather and climate and can obtain images in bad weather and even at night, because of its strong penetrative power (Yamaguchi 2012; Balz and Liao 2010), so it has become a reliable remote sensing data source for acquiring the damage information of earthquake-stricken areas (Dell'Acqua and Polli 2011). Compared to single-polarization synthetic 
aperture radar (SAR), fully polarimetric SAR (PolSAR) is capable of recording the backward scattering information in four kinds of polarization mode, which contain much more information and are more helpful for understanding the characteristics of ground objects (Lee and Pottier 2009; Zhai et al. 2016a).

After the 2011 Tohoku earthquake, many scholars analyzed and studied the earthquake damage characteristics and the disaster investigation using airborne and satellite PolSAR data. Most of these studies were carried out mainly based on the changes of polarimetric features between pre- and post-earthquake using multi-temporal PolSAR data (Chen and Sato 2013; Park et al. 2013; Sato et al. 2012; Watanabe et al. 2012). However, archived pre-event PolSAR images matched with the post-event images are often difficult to obtain, and the registration of the pre- and post-event PolSAR images also costs time and manpower. Therefore, earthquake damage assessment using only a single post-earthquake PolSAR image has attracted the attention of more and more researchers. Guo et al. (2012) and Li et al. (2012) introduced the circular polarization correlation coefficient $\rho$ and proposed the $H-\alpha-\rho$ method to extract collapsed building information using RADARSAT-2 polarimetric data after the "4.14" Yushu earthquake. Zhao et al. (2013) introduced the texture parameter of homogeneity to improve the $H$ $\alpha-\rho$ method using high-resolution airborne PolSAR data. Shen et al. (2015) used the method of image retrieval based on feature template matching to extract the collapsed building information. Zhai et al. (2016b) used the two parameters of the normalized difference of the dihedral component $(N D D C)$ and the $\mathrm{HH}-\mathrm{HV}$ correlation coefficient $\left(\rho_{\mathrm{HHHV}}\right)$ to correct the result of Wishart supervised classification and extracted the collapsed buildings, and the high accuracy for building earthquake damage information extraction was acquired eventually.

This study is devoted to extracting building damage information using a single post-earthquake PolSAR image. In a PolSAR image, the uncollapsed parallel buildings whose array direction is parallel to the flight direction are dihedral dominated, so their scattering power is strong. The collapsed buildings are mainly characterized by volume scattering due to the destruction of the building structure. The uncollapsed oriented buildings that are not parallel to the flight pass of the radar can cause polarization orientation angle (POA) shift and higher cross-polarization component. The scattering mechanism ambiguity between the oriented buildings and the collapsed buildings is present in the traditional modelbased decomposition. That way, the oriented buildings are very similar to collapsed buildings in PolSAR images. If the traditional polarimetric classification methods are used to extract the collapsed buildings, the oriented buildings can be easily misclassified as collapsed buildings, and the building collapse rate is likely to be overestimated. Although there are some advanced model-based decompositions reported to avoid the scattering mechanism ambiguities, especially among oriented buildings (Chen et al. 2014a, b), the scattering mechanism ambiguities cannot be avoided for the oriented building patches with big POA. In view of this, the scheme of POA compensation is carried out to enhance the double-bounce scattering power of the oriented buildings in our study (Yamaguchi et al. 2011), and the difference in the change rate of the relative contributions of double-bounce scattering and volume scattering, $\mathrm{CR}_{\mathrm{Dbl}-\mathrm{Vol}}$, is introduced to help to distinguish the two types of buildings based on the scheme of POA compensation. The experiments show that the building damage assessment accuracy can be improved using the method proposed in this paper.

\section{Methodology POA compensation}

The uncollapsed buildings in earthquake-stricken areas consist of both parallel buildings and oriented buildings. The scattering power of parallel buildings is particularly strong because they form a dihedral structure with the ground, but the scattering power of oriented buildings is as weak as the collapsed buildings. If the oriented buildings are not differentiated from the collapsed buildings, the building damage will be greatly overestimated, especially in built-up areas containing many oriented buildings. Compensating the POA shift induced by the polarization basis being rotated can enhance the doublebounce scattering power of the oriented buildings.

The POA shift $\theta$ is defined as the angle between the major axis of the polarization ellipse and the horizontal axis (Iribe and Sato 2007). It can be expressed as (Lee et al. 2000):

$$
\tan \theta=\frac{\tan \omega}{-\tan \gamma \cos \phi+\sin \phi}
$$

where $\theta$ is the POA shift, $\tan \omega$ is the azimuth slope, $\tan \gamma$ is the slope in the ground range direction, and $\phi$ is the radar look angle.

The following is the process of deriving the POA shift. The POA is estimated as:

$$
\theta= \begin{cases}\theta_{0}, & \text { if } \quad \theta_{0} \leq \frac{\pi}{4} \\ \theta_{0}-\frac{\pi}{2}, & \text { if } \quad \theta_{0}>\frac{\pi}{4}\end{cases}
$$

where

$$
\theta_{0}=\frac{1}{4}\left[\operatorname{Arg}\left(\left\langle S_{\mathrm{RR}} S_{\mathrm{LL}}^{*}\right\rangle\right)+\pi\right]
$$


The two circular components, $S_{\mathrm{RR}}$ and $S_{\mathrm{LL}}$, can be obtained from the linear polarization terms (Kimura et al. 2005; Lee and Ainsworth 2011):

$$
\begin{aligned}
& S_{\mathrm{RR}}=\frac{1}{2}\left(S_{\mathrm{HH}}-S_{\mathrm{VV}}+i 2 S_{\mathrm{HV}}\right) \\
& S_{\mathrm{LL}}=\frac{1}{2}\left(S_{\mathrm{VV}}-S_{\mathrm{HH}}+i 2 S_{\mathrm{HV}}\right)
\end{aligned}
$$

It is easier to compute the POA of the circular polarization using Eq. (4). The data compensation can be achieved by (Lee et al. 2014):

$$
T_{\theta}=R(\theta) T R(\theta)^{T} .
$$

where $T_{\theta}$ is the compensated matrix for the orientation angle of $\theta$, the matrix $T$ is a single-look or multi-look processed coherency matrix, the superscript $T$ denotes the matrix transpose, and the rotation matrix $R(\theta)$ is given by (Chen et al. 2013, 2014c):

$$
R(\theta)=\left[\begin{array}{ccc}
1 & 0 & 0 \\
0 & \cos 2 \theta & \sin 2 \theta \\
0 & -\sin 2 \theta & \cos 2 \theta
\end{array}\right] .
$$

\section{Wishart supervised classification}

Wishart supervised classification (Lee and Grunes 1992; Lee et al. 1994, 1998, 1999) uses a maximum likelihood classifier based on the statistical properties to perform supervised classification under the assumption of the probability density distribution function of the polarimetric covariance matrix following a complex Wishart probability distribution with $n$ degrees of freedom, $W_{C}(n,[C])$ (Lee et al. 1994, 1999; Lee and Pottier 2009). The complex Wishart classifier is one of the most widely used and the most suitable classifiers in the application of PolSAR image supervised classification, and it can make full use of the intensity information and phase information of PolSAR data. In the process of Wishart supervised classification, the covariance matrix of the class center of the $k$ th class is estimated by training samples and is defined as $\left[\sum_{k}\right]$, and the Wishart distance between pixel $[C]$ of the test samples and the $k$ th class can be expressed as:

$$
d\left([C] \mid\left[\Sigma_{k}\right]\right)=\ln \left|\left[\Sigma_{k}\right]\right|+\operatorname{Tr}\left(\left[\Sigma_{k}\right]^{-1}[C]\right)
$$

where $\operatorname{Tr}\left(\left[\sum_{k}\right]^{-1}[C]\right)$ stands for the trace of $\left[\sum_{k}\right]^{-1}[C]$, and the superscript -1 denotes the matrix inversion.

In each iteration, the Wishart distance $d\left([C] \mid\left[\sum_{i}\right]\right)$ between each pixel in the test samples and each category is calculated, and the pixel is then classified as the class with the minimum Wishart distance.

Because the double-bounce scattering power of oriented buildings is enhanced after POA compensation, the Wishart supervised classification is performed on the PolSAR data after POA compensation, which can obtain a higher accuracy than before POA compensation. For the study area in this paper, the ground objects can be classified into four classes-bare areas, parallel buildings, oriented buildings, and collapsed buildings-using the Wishart supervised classification.

\section{Analysis of building scattering components in earthquake-stricken areas}

The buildings of earthquake-stricken areas are divided into three classes in this paper, based on the characteristics of the PolSAR images: collapsed buildings, parallel buildings, and oriented buildings. In order to comprehend the changes in the scattering mechanism after POA compensation for the three kinds of buildings, the four scattering components generated from Yamaguchi fourcomponent decomposition, before and after POA compensation, are analyzed in this section.

According to the Yamaguchi four-component scattering model (Yamaguchi et al. 2005, 2006, 2011), the scattering components of the objects are decomposed into surface, double bounce, volume, and helix scattering components. In this paper, the change of scattering components before and after POA compensation is employed to define the parameter $\mathrm{CR}_{\mathrm{Dbl}-\mathrm{Vol}}$, so the traditional Yamaguchi fourcomponent decomposition (Yamaguchi et al. 2005, 2006) is used for the four components extraction. The different volume scattering models are chosen according to the value of $R=10 \log \left(\left|S_{\mathrm{VV}}\right|^{2} /\left|S_{\mathrm{HH}}\right|^{2}\right)$ in the traditional Yamaguchi four-component decomposition. For example,

$$
\text { if } \begin{aligned}
R>2 \mathrm{~dB} \\
\langle[C]\rangle=f_{\mathrm{s}}\langle[C]\rangle_{\mathrm{s}}+f_{\mathrm{d}}\langle[C]\rangle_{\mathrm{d}}+f_{\mathrm{v}}\langle[C]\rangle_{\mathrm{v}}+f_{\mathrm{h}}\langle[C]\rangle_{\mathrm{h}} \\
=f_{\mathrm{s}}\left[\begin{array}{ccc}
|\beta|^{2} & 0 & \beta \\
0 & 0 & 0 \\
\beta^{*} & 0 & 1
\end{array}\right]+f_{\mathrm{d}}\left[\begin{array}{ccc}
|\alpha|^{2} & 0 & \alpha \\
0 & 0 & 0 \\
\alpha^{*} & 0 & 1
\end{array}\right]+\frac{f_{\mathrm{v}}}{15}\left[\begin{array}{lll}
8 & 0 & 2 \\
0 & 4 & 0 \\
2 & 0 & 3
\end{array}\right] \\
+\frac{f_{\mathrm{h}}}{4}\left[\begin{array}{ccc}
1 & \pm j \sqrt{2} & -1 \\
\mp j \sqrt{2} & 2 & \pm j \sqrt{2} \\
-1 & \mp j \sqrt{2} & 1
\end{array}\right]
\end{aligned}
$$

where $[C]$ is the covariance matrix of the PolSAR data; \langle\rangle denotes the ensemble average in the data processing; and the expansion coefficients $f_{\mathrm{s}}, f_{\mathrm{d}}, f_{\mathrm{v}}$, and $f_{\mathrm{h}}$ correspond to the contribution of the surface, double bounce, volume, and helix scattering components, respectively. The scattering powers $P_{\mathrm{s}}, P_{\mathrm{d}}, P_{\mathrm{v}}$, and $P_{\mathrm{h}}$, corresponding to the surface, double bounce, volume, and helix scattering components, respectively, are obtained as:

$$
\left\{\begin{array}{l}
P_{\mathrm{s}}=f_{\mathrm{s}}\left(1+|\beta|^{2}\right) \\
P_{\mathrm{d}}=f_{\mathrm{d}}\left(1+|\alpha|^{2}\right) \\
P_{\mathrm{v}}=f_{\mathrm{v}} \\
P_{\mathrm{h}}=f_{\mathrm{h}} \\
P=P_{\mathrm{s}}+P_{\mathrm{d}}+P_{\mathrm{v}}+P_{\mathrm{h}}=\left\langle\left|S_{\mathrm{HH}}\right|^{2}+2\left|S_{\mathrm{HV}}\right|^{2}+\left|S_{\mathrm{VV}}\right|^{2}\right\rangle
\end{array}\right.
$$


The relative contributions of the four components of the three kinds of building samples selected in Fig. 4, before and after POA compensation, are shown in Fig. 1. For more validations, there are two samples of the collapsed buildings in different regions and two samples of the oriented buildings in different regions with different orientations selected in Fig. 4. As shown in Fig. 1, the dominant scattering component of the parallel buildings is double-bounce scattering, and the oriented buildings and the collapsed buildings are dominated by the volume scattering component. Before and after POA compensation, the relative contributions of each scattering component for the parallel buildings basically remain the same, while the relative contribution of double-bounce scattering for the oriented buildings is more than doubles, and the relative contribution of volume scattering significantly decreases. In addition, for the collapsed buildings, the relative contribution of double-bounce scattering also increases, but the increase is less than for the oriented buildings, and the decrease in the relative contribution of volume scattering is very small. Furthermore, comparing
Fig. 1(b1) with Fig. 1(b2, c1) with Fig. 1(c2), the above analyzation is confirmed by the two samples of collapsed buildings with no. 1 and no. 2 and the two samples of oriented buildings with no. 1 and no. 2. In conclusion, for the oriented buildings, the scheme of POA compensation can greatly improve the relative contribution of the double-bounce scattering component and can significantly reduce the relative contribution of the volume scattering component.

Inspired by the conclusion deduced from Fig. 1, the change rates of the relative contribution before and after POA compensation for the double-bounce scattering component and the volume scattering component are proposed and defined as:

$$
\mathrm{CR}_{\mathrm{Dbl}}=\frac{\mathrm{Dbl}_{\mathrm{afterPAC}}-\mathrm{Dbl}_{\text {beforePAC }}}{\text { Dbl }_{\text {beforePAC }}}
$$

where $\mathrm{CR}_{\mathrm{Dbl}}$ is the change rate of the relative contribution of the double-bounce scattering component, $\mathrm{Dbl}_{\text {beforePAC }}$ denotes the relative contribution of the double-bounce scattering component before POA compensation, and

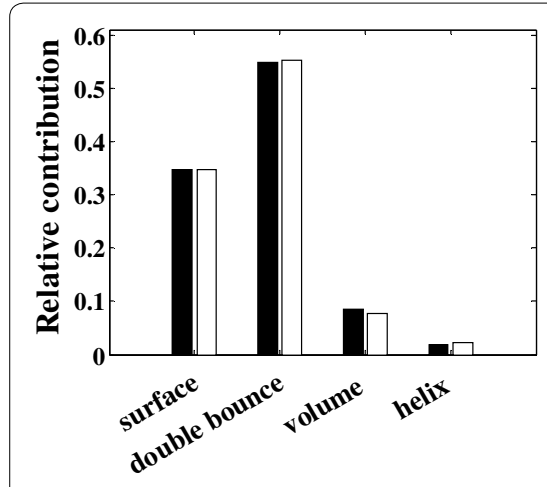

a Parallel buildings

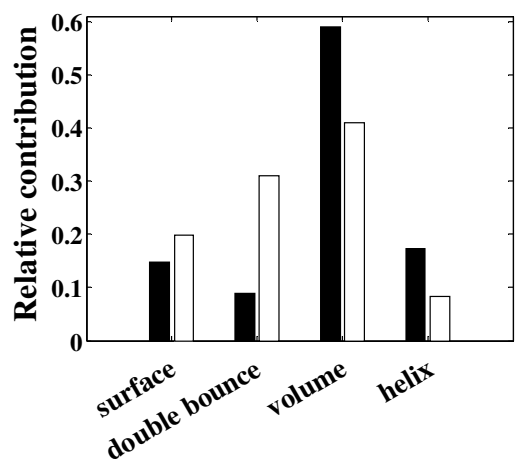

b2 Oriented buildings 2

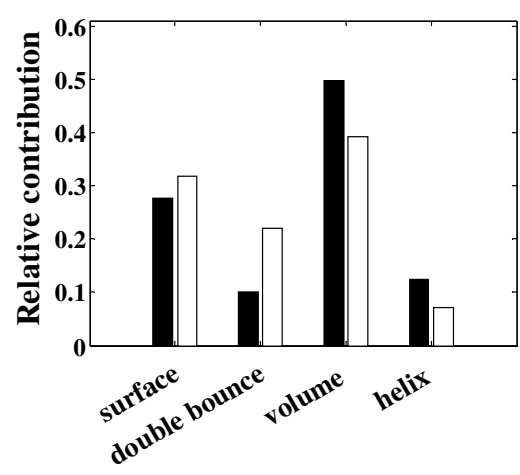

b1 Oriented buildings 1

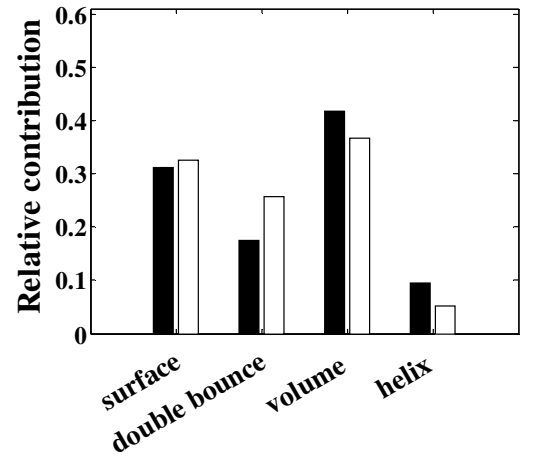

c1 Collapsed buildings 1

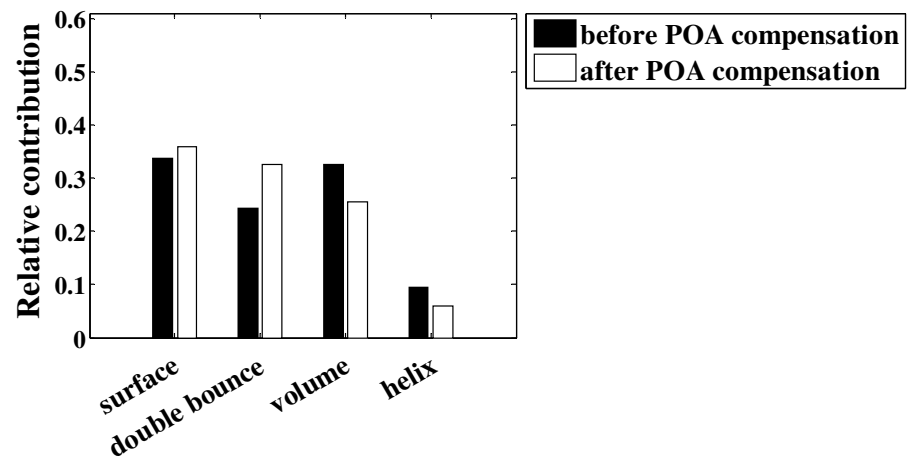

c2 Collapsed buildings 2

Fig. 1 Relative contribution of the different scattering mechanisms of the three kinds of buildings before and after POA compensation. a Parallel buildings represents the sample of the parallel buildings in Fig. 4. b1 Oriented buildings 1, b2 oriented buildings 2, c1 collapsed buildings 1 , and $\mathbf{c 2}$ collapsed buildings 2 represent the sample of the oriented buildings marked with no. 1, the sample of the oriented buildings marked with no. 2, the sample of the collapsed buildings marked with no. 1, and the sample of the collapsed buildings marked with no. 2 in Fig. 4, respectively 
$\mathrm{Dbl}_{\text {afterPAC }}$ is the relative contribution of the doublebounce scattering component after POA compensation.

$$
\mathrm{CR}_{\mathrm{Vol}}=\frac{\text { Vol }_{\text {afterPAC }}-\mathrm{Vol}_{\text {beforePAC }}}{\text { Vol }_{\text {beforePAC }}}
$$

where $\mathrm{CR}_{\mathrm{Vol}}$ is the change rate of the relative contribution of the volume scattering component, $\mathrm{Vol}_{\text {beforePAC }}$ denotes the relative contribution of the volume scattering component before POA compensation, and $\mathrm{Vol}_{\text {afterPAC }}$ is the relative contribution of the volume scattering component after POA compensation.

For comparison, the $\mathrm{CR}_{\mathrm{Dbl}}$ and $\mathrm{CR}_{\mathrm{Vol}}$ values of oriented buildings and collapsed buildings are shown in Fig. 2. As shown in both Fig. 2a, b, for the two pairs of the samples of the collapsed buildings and oriented buildings, the $\mathrm{CR}_{\mathrm{Dbl}}$ of oriented buildings is more than twice as large as that of the collapsed buildings, and the amplitude of the $\mathrm{CR}_{\mathrm{Vol}}$ of oriented buildings is also larger than that of collapsed buildings. Therefore, the difference between $\mathrm{CR}_{\mathrm{Dbl}}$ and $\mathrm{CR}_{\mathrm{Vol}}$ is defined as:

$$
\mathrm{CR}_{\mathrm{Dbl}-\mathrm{Vol}}=\mathrm{CR}_{\mathrm{Dbl}}-\mathrm{CR}_{\mathrm{Vol}}
$$

$\mathrm{CR}_{\mathrm{Dbl}-\mathrm{Vol}}$ is actually the difference in the change rate of the relative contribution between the double-bounce and volume scattering components, which is also shown

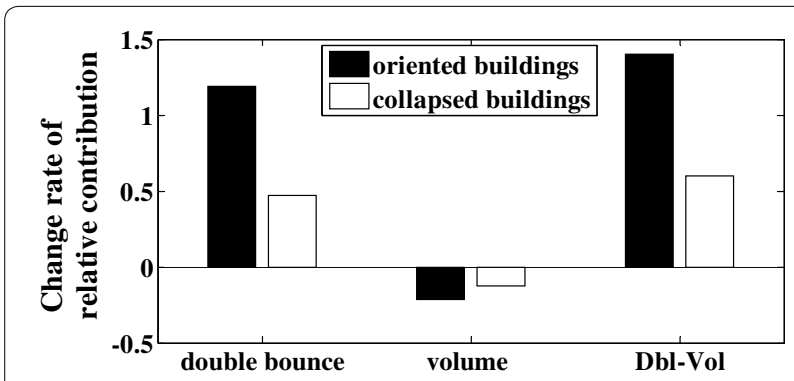

(a)

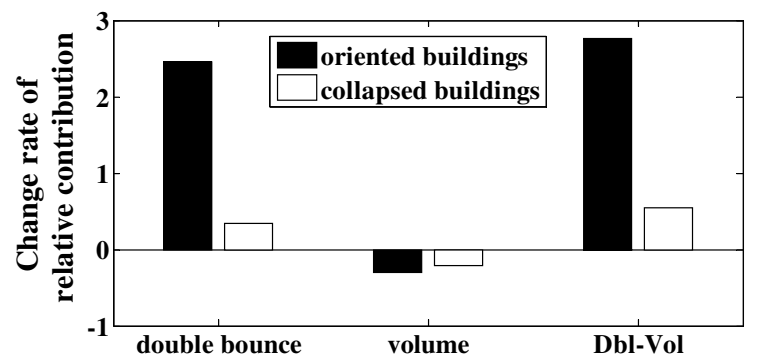

(b)

Fig. 2 Change rate of the relative contribution of the different scattering mechanisms for the oriented and collapsed buildings before and after POA compensation. a Oriented buildings 1 versus collapsed buildings 1. b Oriented buildings 2 versus collapsed buildings 2 in Fig. 2. The difference in $\mathrm{CR}_{\mathrm{Dbl}-\mathrm{Vol}}$ between collapsed buildings and oriented buildings is more distinct than the difference in $\mathrm{CR}_{\mathrm{Dbl}}$ and the difference in $\mathrm{CR}_{\mathrm{Vol}}$. In Fig. 2, both of the two pairs of the samples of the collapsed buildings and oriented buildings have shown that the $\mathrm{CR}_{\mathrm{Dbl}-\mathrm{Vol}}$ of oriented buildings is much greater than the $\mathrm{CR}_{\mathrm{Dbl}-\mathrm{Vol}}$ of collapsed buildings. Therefore, $\mathrm{CR}_{\mathrm{Dbl}-\mathrm{Vol}} \mathrm{can}$ be used distinguish the oriented buildings from the collapsed buildings.

After an earthquake, the walls and the regular geometric structure of collapsed buildings are damaged, and the most of the collapsed buildings is the ruins, so the dominant scattering mechanism collapsed buildings can be approximately regarded as the volume scattering from randomly oriented dipoles. Because most of the collapsed buildings are ruins, there is little POA shift for the collapsed buildings, and the implementation of POA compensation cannot greatly change the power of scattering components of the collapsed buildings. However, because of the POA shift of oriented buildings, the employment of POA compensation can enhance the double-bounce scattering power and weaken the volume scattering power. That is, the implementation of POA compensation can greatly change the power of scattering components of the oriented buildings. Therefore, all of the amplitude values of $\mathrm{CR}_{\mathrm{Db}}, \mathrm{CR}_{\mathrm{Vol}}$, and $\mathrm{CR}_{\mathrm{Dbl}-\mathrm{Vol}}$ of the oriented buildings are greater than those of the collapsed buildings. The difference of $\mathrm{CR}_{\mathrm{Db}}, \mathrm{CR}_{\mathrm{Vol}}$, and $\mathrm{CR}_{\mathrm{Dbl}-\mathrm{Vol}}$ between the collapsed buildings and oriented buildings can be used to distinguish them. During the three parameters of $\mathrm{CR}_{\mathrm{Db}}, \mathrm{CR}_{\mathrm{Vol}}$, and $\mathrm{CR}_{\mathrm{Dbl}-\mathrm{Vol}}$, the difference of $\mathrm{CR}_{\mathrm{Dbl}-\mathrm{Vol}}$ between the collapsed buildings and oriented buildings is greatest, so $\mathrm{CR}_{\mathrm{Dbl}-\mathrm{Vol}_{\mathrm{pl}}}$ is used to discriminate the collapsed buildings in this paper.

As shown in Fig. 1, the relative contribution of the double-bounce scattering component of the oriented buildings after POA compensation cannot be increased as much as for the parallel buildings. Therefore, the classification result of the oriented and collapsed buildings generated from the Wishart supervised classification performed on the PolSAR data after POA compensation is still not very accurate. However, the difference in $\mathrm{CR}_{\mathrm{Dbl}-\mathrm{Vol}}$ between the oriented buildings and the collapsed buildings can be used to distinguish the two kinds of buildings and to correct the results of the two kinds of buildings obtained from Wishart supervised classification, so as to improve the accuracy of the collapsed building extraction. Using $\mathrm{CR}_{\mathrm{Dbl}-\mathrm{Vol}}$ to separate the two kinds of buildings can be expressed as:

$$
\begin{cases}\text { if } & \mathrm{CR}_{\mathrm{Dbl}-\mathrm{Vol}}>\varepsilon, x \in \text { oriented buildings } \\ \text { if } & \mathrm{CR}_{\mathrm{Dbl}-\mathrm{Vol}} \leq \varepsilon, x \in \text { collapsed buildings }\end{cases}
$$


where $\varepsilon$ is the threshold value of $\mathrm{CR}_{\mathrm{Dbl}-\mathrm{Vol}}$ set according to experiment, and $x$ is a pixel of the PolSAR image.

\section{Building collapse rate calculation}

The building collapse rate is calculated at the scale of the city block and is defined as the ratio of the collapsed buildings to the total buildings of one block. The total buildings are the sum of the undamaged buildings and the collapsed buildings. The damage level of one block can be indexed by the building collapse rate. Each block is assigned a building block collapse rate $(B B C R)$ to assess the damage level of the block. The $B B C R$ is expressed as:

$$
\mathrm{BBCR}_{j}=\frac{\sum_{i} C_{i j}}{\sum_{i} U_{i j}+\sum_{i} C_{i j}}
$$

where $\mathrm{BBCR}_{j}$ is the BBCR of the $j$ th block; $C_{i j}$ indicates whether pixel $i$ in the $j$ th block belongs to a collapsed building or not, with values of 1 or $0 ; U_{i j}$ indicates whether pixel $i$ in the $j$ th block belongs to an undamaged building or not, with values of 1 or 0 .

\section{Building earthquake damage information extraction}

The process of building damage information extraction is shown in Fig. 3. Firstly, POA compensation is performed on the PolSAR data after preprocessing (Ma et al. 2015), and the new $[C]$ matrix is obtained.

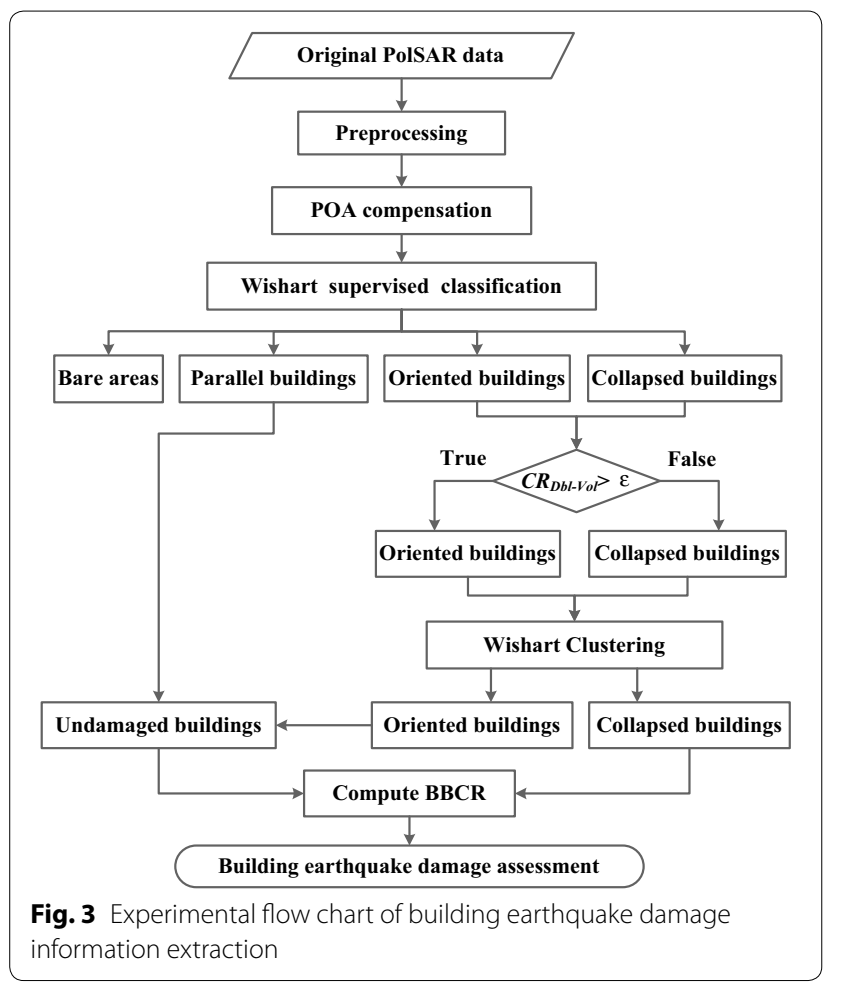

Secondly, according to the case study selected in this paper, the ground objects in the earthquake-stricken area are classified as bare areas, collapsed buildings, parallel buildings, and oriented buildings, using the Wishart supervised classification implemented on the PolSAR data after PolSAR compensation.

Thirdly, the values of $\mathrm{CR}_{\mathrm{Dbl}-\mathrm{Vol}}$ of the collapsed buildings and oriented buildings are calculated, and the threshold value $\varepsilon$ is set to separate the two kinds of buildings according to the difference in $\mathrm{CR}_{\mathrm{Dbl}-\mathrm{Vol}}$ between the collapsed buildings and the oriented buildings, as shown in Fig. 2. In this way, the new class centers for the two kinds of buildings are obtained. The clustering and iteration using the complex Wishart classifier then need to be carried out again to update the new class centers. After this, the two classes of collapsed buildings and oriented buildings generated from the Wishart supervised classification are corrected, and the building damage information extraction is more accurate.

Finally, the parallel buildings and the oriented buildings are combined as the undamaged buildings, and the BBCR of each city block can be calculated. The damage levels of the buildings are then divided into slight, moderate, and serious damage levels according to the threshold values of the BBCR.

\section{Experiment and analysis}

\section{Experimental data}

In this paper, the selected case study is the Yushu earthquake of magnitude 7.1 that occurred in Yushu County, Qinghai province, China, on April 14, 2010. The location of the epicenter was $33.1^{\circ} \mathrm{N}$ and $96.6^{\circ} \mathrm{E}$. There were many collapsed buildings, and more than 2600 people died in the earthquake. The direct economic losses amounted to more than 22 billion CNY. The study area is the urban region of Yushu County. The vegetation is very sparse and low-level in this urban region, so it was ignored in the experiment. The buildings are mainly low-rise rural residential buildings in Yushu County.

The experimental data are the airborne high-resolution PolSAR image acquired one day after the earthquake in the P-band by the Chinese airborne SAR mapping system (SARMapper). Both the range resolution and azimuth resolution are approximately $1 \mathrm{~m}$. The flight pass was in an east-west horizontal direction. The Pauli RGB image is shown in Fig. 4, formed as a color composite of $|\mathrm{HH}-\mathrm{VV}|$ (red), $|\mathrm{HV}|$ (green), and $|\mathrm{HH}+\mathrm{VV}|$ (blue), with the size of $8192 \times 4384$ pixels. The five regions of interest (ROIs) for three kinds of buildings marked in Fig. 4 with the five colored rectangles are the samples of collapsed buildings in red, oriented buildings in blue, and parallel buildings in orange. In Fig. 4, the buildings in the two regions of the oriented buildings with 


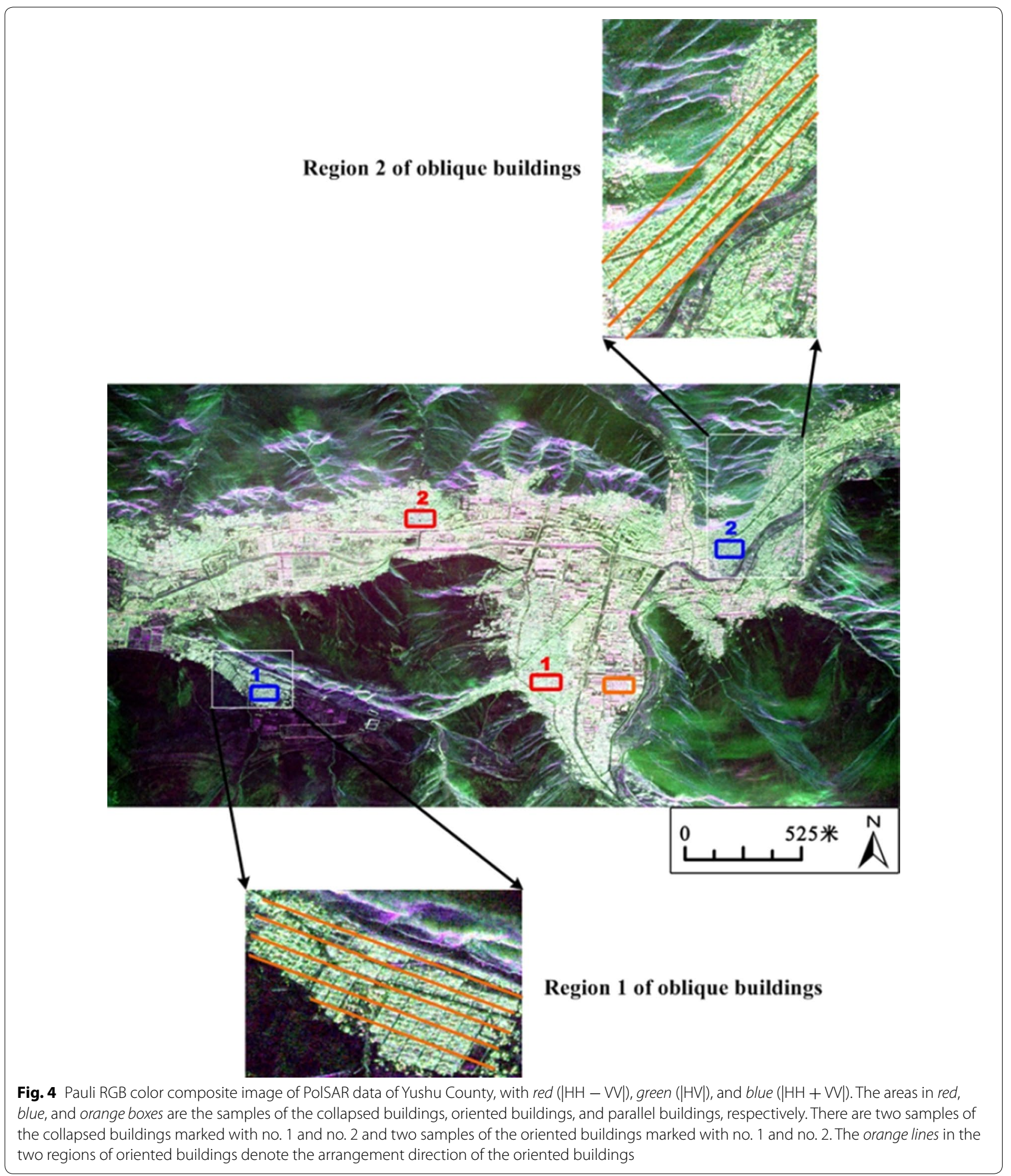

white rectangles have different orientations, and the arrangement direction of each region is shown with the orange lines. The orientations of the oriented buildings in the Yushu earthquake-stricken areas mainly exist in the two regions of the oriented buildings in Fig. 4. The samples marked with no. 1 and no. 2 are selected in the two regions of the oriented buildings, and the two samples represent different orientations. According to the 
observation of Fig. 2a, b and the conclusion of "Analysis of building scattering components in earthquake-stricken areas" section, the difference of $\mathrm{CR}_{\mathrm{Dbl}-\mathrm{Vol}}$ between the collapsed buildings and the oriented buildings is significant, although the orientations are different for the two samples of oriented buildings. Therefore, the difference of the orientations for the oriented buildings has no influence on using $\mathrm{CR}_{\mathrm{Dbl}-\mathrm{Vol}}$ to distinguish the collapsed buildings and the oriented buildings.

In the PolSAR data, the mountains surrounding the urban area were removed by masking, and only the urban region was kept. The whole urban region was divided into 72 city blocks by roads and according to the similarity of the built-up patches. The earthquake damage assessment reference information is shown in Fig. 5 according to Guo et al. (2010) and the China Earthquake Administration (2010). The building damage levels of the 72 city blocks were divided into slight, moderate, and serious damage levels. If more than half of buildings collapsed after the earthquake, the city block was considered as serious damage. The city block with less than one-third buildings collapsing was considered as slight damage. The city block with the damage level between slight damage and serious damage was considered as moderate damage.

\section{Experimental results}

According to the process of building earthquake damage information extraction shown in Fig. 3, the Wishart supervised classification method was performed on the PolSAR data after POA compensation. In the study area, the vegetation is very sparse and low level and can be ignored, so the non-buildings were mainly composed of bare areas. Therefore, the ground objects were classified into the four classes of bare areas, parallel undamaged buildings, oriented undamaged buildings, and collapsed buildings. We calculated the $\mathrm{CR}_{\mathrm{Dbl}-\mathrm{Vol}}$ for all of the samples of oriented buildings and the collapsed buildings generated from the Wishart supervised classification and set the threshold value $\varepsilon$ of $\mathrm{CR}_{\mathrm{Dbl}-\mathrm{Vol}_{\mathrm{l}}}$ in Eq. (13) as 0.7 according to the difference of the Dbl-Vol values of the oriented buildings and the collapsed buildings shown in Fig. 2. The two kinds of buildings were reclassified based on Eq. (13), as described in "Analysis of building scattering components in earthquake-stricken areas" section, and clustering based on the Wishart distance was performed on the initial classification results, and then, the final classification results of the oriented buildings and the collapsed buildings were obtained. The oriented buildings together with the parallel buildings were considered to be the undamaged buildings.

The results of extracting the collapsed buildings, the undamaged buildings, and the non-buildings are shown in Fig. 6, in which the red areas are the collapsed buildings, the green areas denote the undamaged buildings, and the blue areas correspond to the non-buildings. The BBCR of each block was calculated, and the building damage levels were set as:

$$
\begin{aligned}
& \text { if } \mathrm{BBCR} \leq 0.2, \quad \text { the block } \in \text { slight damage } \\
& \{\text { if } 0.2<B \bar{B} C R \leq 0.5 \text {, the block } \in \text { moderate damage } \\
& \text { if } \mathrm{BBCR}>0.5, \quad \text { the block } \in \text { serious damage }
\end{aligned}
$$

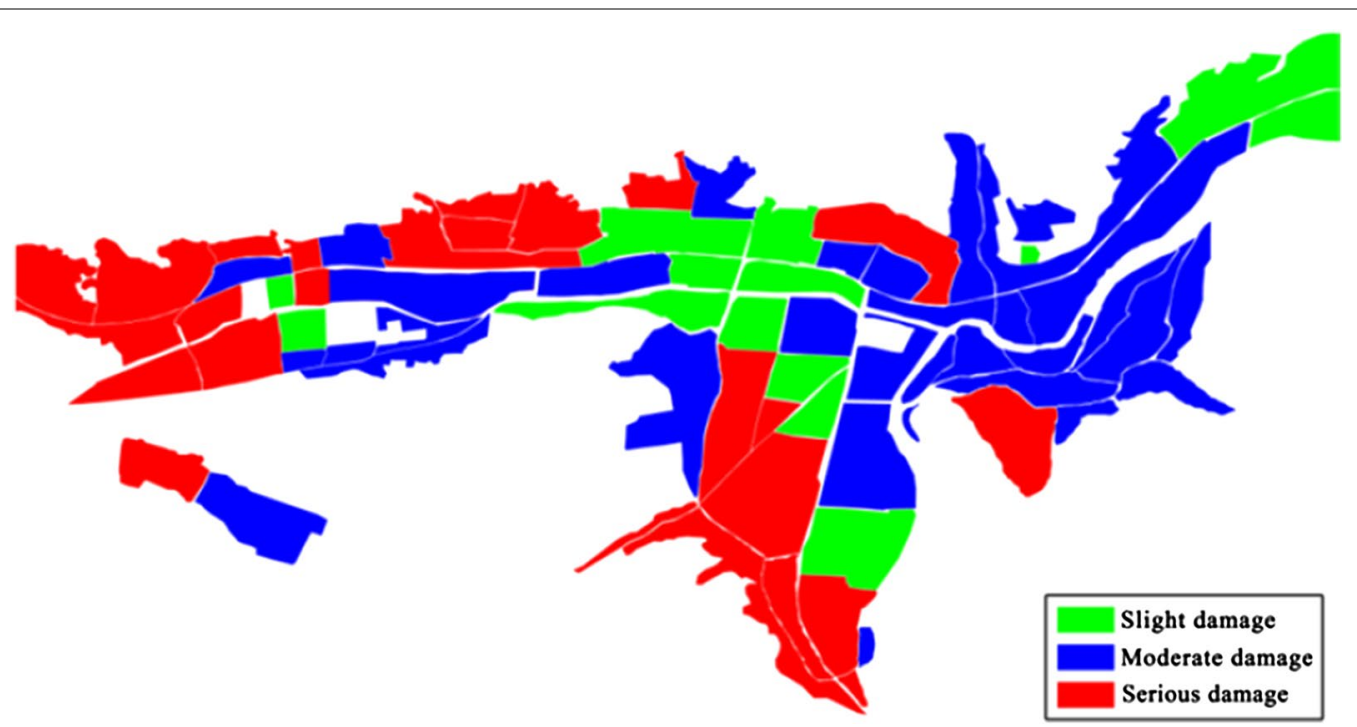

Fig. 5 Reference map of the building earthquake damage information at the city block scale in the Yushu urban region. If more than half of buildings collapsed after the earthquake, the city block was considered as serious damage. The city block with less than one-third buildings collapsing was considered as slight damage. The city block with the damage level between slight damage and serious damage was considered as moderate damage 


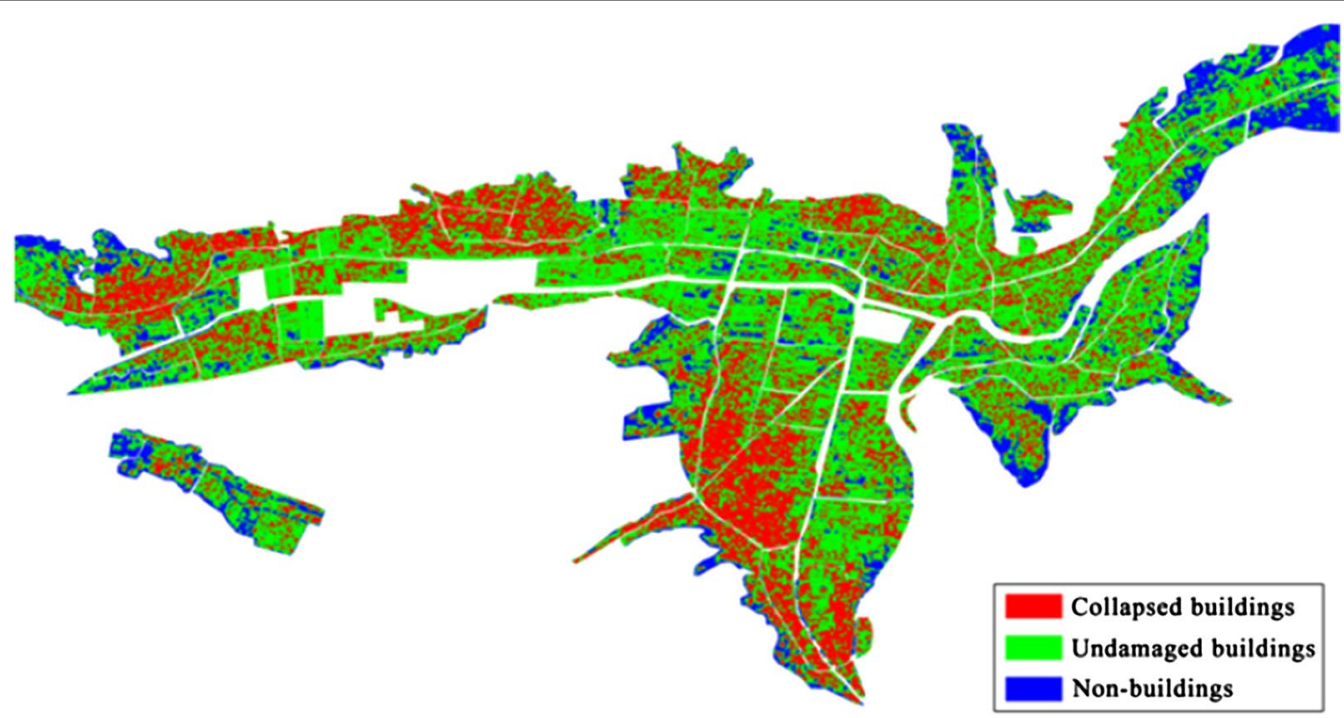

Fig. 6 Experimental results distribution map of the collapsed buildings, the undamaged buildings, and the non-buildings in the earthquakestricken urban area of Yushu County

The map of building damage levels for the whole urban region at the block scale is shown in Fig. 7, where the numbered blocks are the misclassified blocks, and the color of the numbers denotes the correct damage level. For example, the no. 1 block should actually be seriously damaged (red), but is misclassified as moderate damage (blue). The accuracy evaluation of the experimental results is given in Table 1 by reference to Fig. 5. For comparison, the results of both the proposed method and the method using Wishart supervised classification directly without POA compensation and $\mathrm{CR}_{\mathrm{Dbl}-\mathrm{Vol}}$, which is termed direct Wishart supervised classification (DWSC), are listed in Table 1.

\section{Discussion and analysis}

As shown in Fig. 7, there are 15 blocks misclassified. Among them, the blocks with nos. 1-8, which are should be serious damage, are misclassified as moderate damage, and the blocks with nos. 9-12 are misclassified as slight damage, which are should be moderate damage, and the blocks with nos. 13-15, which are should be slight damage, are misclassified as moderate damage. In general, the damage levels of blocks with nos. 1-12 are underestimated, while the damage levels of blocks with nos. 13-15 are overestimated. For most of the misclassified blocks, their damage levels are underestimated, which indicates the oriented buildings are overestimated using the proposed method and the oriented buildings overestimated are mainly the remaining oriented walls of the collapsed buildings.

As given in Table 1, the overall accuracy of the building earthquake damage information extraction was increased by $7 \%$ using the proposed method compared to the DWSC method. There were actually 25 blocks, and 17 blocks were extracted using the proposed method, but 31 blocks were extracted by the DWSC method. Therefore, the proposed method can effectively reduce the overestimation of building earthquake damage. Most of the misclassification situations were those of the slight damage level or the serious damage level being misclassified as the moderate damage level, and the moderate damage level being misclassified as the slight damage level. In other words, the misclassification of the damage level only spanned one level, and there was only one block of serious damage misclassified as the slight damage level. In short, for the 15 misclassified blocks, the main situation of misclassification involved reduced damage levels.

Although POA compensation can enhance the double-bounce scattering power of oriented buildings, the dominant scattering mechanism of oriented buildings is still volume scattering, and the scattering power is still weaker than for parallel buildings. Therefore, there are still many oriented buildings and collapsed buildings mixed up with each other in the classification results of the Wishart supervised classification performed on the PolSAR data after POA compensation. Accordingly, the difference in $\mathrm{CR}_{\mathrm{Dbl}-\mathrm{Vol}}$ between oriented buildings and collapsed buildings is used to correct the results of the Wishart supervised classification.

However, the correction can result in the oriented buildings being detected too much and can result in overestimation of the undamaged buildings. This is influenced by the selection of the $\mathrm{CR}_{\mathrm{Dbl}-\mathrm{Vol}}$ threshold value $\varepsilon$ for 


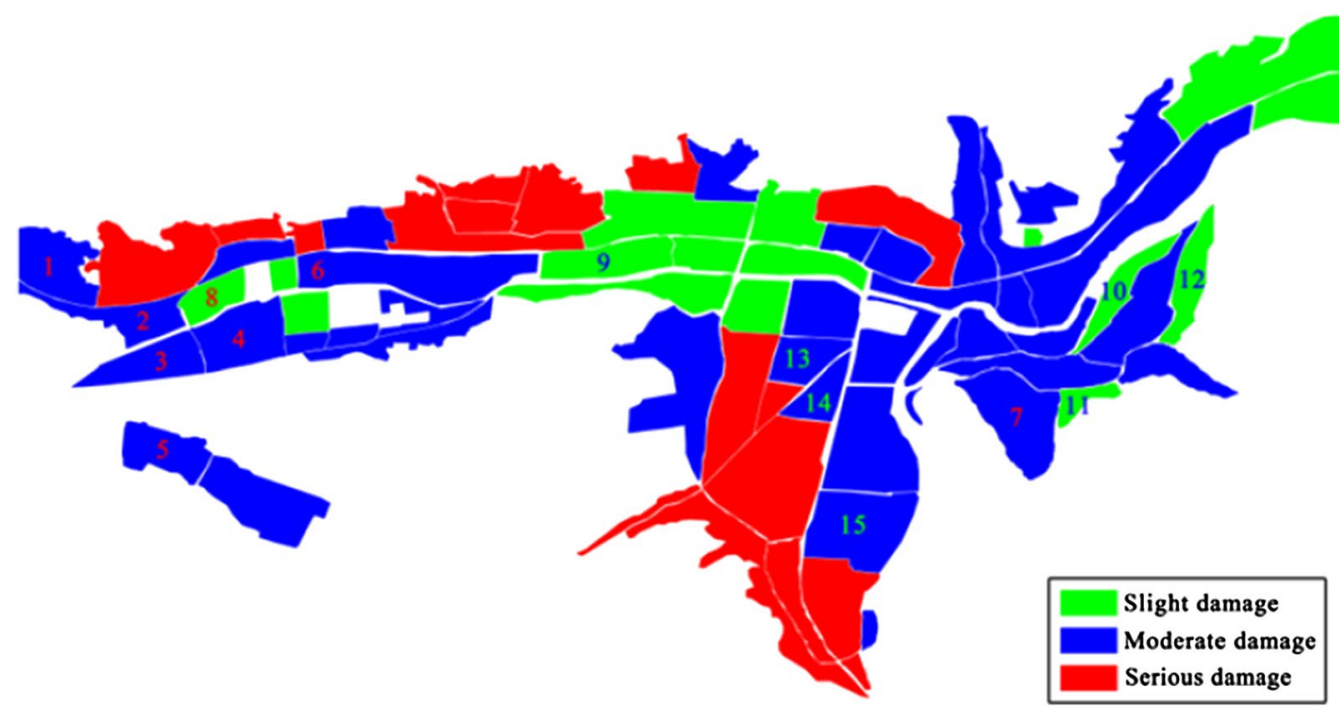

Fig. 7 Experimental results map of the building damage levels at the block scale in the Yushu urban region. The numbered blocks are misclassified, and the color of the numbers denotes the color of the correct damage level

Table 1 Accuracy evaluation of the earthquake damage information extraction of the two methods

\begin{tabular}{|c|c|c|c|c|c|c|}
\hline & \multicolumn{3}{|c|}{ The proposed method } & \multicolumn{3}{|l|}{ DWSC } \\
\hline & \multicolumn{6}{|l|}{ (Experiment) } \\
\hline & SLD (no. of blocks) & MOD (no. of blocks) & SED (no. of blocks) & SLD (no. of blocks) & MOD (no. of blocks) & SED (no. of blocks) \\
\hline \multicolumn{7}{|c|}{ (Reference) } \\
\hline SLD & 11 & 3 & 0 & 9 & 3 & 2 \\
\hline MOD & 4 & 29 & 0 & 3 & 22 & 8 \\
\hline \multirow[t]{2}{*}{ SED } & 1 & 7 & 17 & 0 & 4 & 21 \\
\hline & \multicolumn{3}{|l|}{ OA: $79.2 \%$} & \multicolumn{3}{|l|}{ OA: $72.2 \%$} \\
\hline
\end{tabular}

separating oriented buildings and collapsed buildings and is the main reason why the building damage levels of the blocks are reduced. In addition, due to the fact that some residual walls of the collapsed buildings form a dihedral structure with the ground, some collapsed building areas also have high double-bounce scattering power, and these areas are easily misclassified as undamaged parallel buildings. In the collapsed building areas, the doublebounce scattering power of some oriented residual walls is increased after POA compensation, and these walls may also be misclassified as parallel buildings. These are the causes of the overestimation of the undamaged buildings.

The overestimation of the undamaged buildings gives rise to a reduction in the building damage level, and the identification accuracy of the blocks with the serious damage level is reduced. However, the identification accuracy of the blocks with the slight damage level and moderate damage level is generally improved, and the overall accuracy is improved.

\section{Conclusion}

In this paper, building earthquake damage information has been extracted using a single post-event PolSAR image. Because the characteristics of oriented buildings are very similar to the collapsed buildings in PolSAR images, and the double-bounce scattering power of oriented buildings is weak, the scheme of POA compensation is performed on the PolSAR image to enhance the double-bounce scattering power of the oriented buildings. Although both the scattering power and the relative contribution of the double-bounce scattering component of oriented buildings in the PolSAR image after POA compensation are increased, the dominant scattering mechanism of oriented buildings is still volume scattering. Therefore, the results of the Wishart supervised classification are not very accurate and need to be improved. Through analyzing the changes in the scattering mechanism before and after POA compensation for the three kinds of buildings, we found that the increase 
in the amount of double-bounce scattering component and the reduction in the amplitude of the volume scattering component of the oriented buildings are greater than for the collapsed buildings. Accordingly, the parameter of $\mathrm{CR}_{\mathrm{Dbl}-\mathrm{Vol}}$ is proposed to further distinguish the oriented buildings from the collapsed buildings. Therefore, the significant difference in $\mathrm{CR}_{\mathrm{Dbl}-\mathrm{Vol}}$ between collapsed buildings and oriented buildings is used to correct the results of the Wishart supervised classification for the two kinds of buildings, and the collapsed building extraction accuracy is improved. In comparison with the DWSC method, it was found that the proposed method can improve the accuracy of building earthquake damage assessment.

\section{Authors' contributions}

WZ drafted the manuscript and was responsible for the research design, writing the source code, data analysis, and interpretation of the results. $\mathrm{CH}$ revised the paper and participated in the design of the study and the accuracy assessment experiments. Both authors read and approved the final manuscript.

\section{Author details \\ ${ }^{1}$ Gansu Earthquake Administration, Lanzhou 730000, Gansu, China. ${ }^{2}$ Key Lab- oratory of Remote Sensing of Gansu Province, Heihe Remote Sensing Experi- mental Research Station, Cold and Arid Regions Environmental and Engi- neering Research Institute, Chinese Academy of Sciences, Lanzhou 730000 Gansu, China. ${ }^{3}$ College of Resources and Environment, University of Chinese Academy of Sciences, Beijing 100049, China.}

\section{Acknowledgements \\ This work was supported by the Hundred Talent Program of the Chinese Academy of Sciences (29Y127D01); the Cross-disciplinary Collaborative Teams Program for Science, Technology and Innovation of the Chinese Academy of Sciences; the Earthquake Science and Technology Development Fund Pro- gram of Lanzhou Earthquake Research Institute, China Earthquake Administra- tion (2015M02); the Object-oriented High Trusted SAR Processing System of the National 863 Subject Program; and the Airborne Multiband Polarimetric Interferometric SAR Mapping System of the National Major Surveying and Mapping Science and Technology Special Program. We would also like to thank the anonymous reviewers for their advice on improving the quality of this paper.}

Received: 26 December 2015 Accepted: 10 May 2016 Published online: 23 May 2016

\section{References}

Balz T, Liao M (2010) Building-damage detection using post-seismic highresolution SAR satellite data. Int J Remote Sens 31(13):3369-3391. doi:10.1080/01431161003727671

Chen SW, Sato M (2013) Tsunami damage investigation of built-up areas using multitemporal spaceborne full polarimetric SAR images. IEEE Trans Geosci Remote Sens 51(4):1985-1997. doi:10.1109/ TGRS.2012.2210050

Chen SW, Ohki M, Shimada M et al (2013) Deorientation effect investigation for model-based decomposition over oriented built-up areas. IEEE Trans Geosci Remote Sens 10(2):273-277. doi:10.1109/LGRS.2012.2203577

Chen SW, Wang XS, Li YZ et al (2014a) Adaptive model-based polarimetric decomposition using PollnSAR coherence. IEEE Trans Geosci Remote Sens 52(3):1705-1718. doi:10.1109/TGRS.2013.2253780

Chen SW, Li YZ, Wang XS et al (2014b) Modeling and interpretation of scattering mechanisms in polarimetric synthetic aperture radar: advances and perspectives. IEEE Signal Process Mag 31(4):79-89. doi:10.1109/ MSP.2014.2312099
Chen SW, Wang XS, Xiao SP et al (2014c) General polarimetric model-based decomposition for coherency matrix. IEEE Trans Geosci Remote Sens 52(3):1843-1855. doi:10.1109/TGRS.2013.2255615

China Earthquake Administration (2010) Preliminary remote sensing results of Qinghai Yushu earthquake emergency. http://www.cea. gov.cn/manage/html/8a8587881632fa5c0116674a018300cf/_content/10_04/17/1271485532211.html. Accessed 20 Nov 2015

de Michele M, Raucoules D, Lasserre C et al (2010) The Mw 7.9, 12 May 2008 Sichuan earthquake rupture measured by sub-pixel correlation of ALOS PALSAR amplitude images. Earth Planets Space 62(11):875-879. doi:10.5047/eps.2009.05.002

Dell'Acqua F, Polli DA (2011) Post-event only VHR radar satellite data for automated damage assessment. Photogramm Eng Remote Sens 77(10):10371043. doi:10.14358/PERS.77.10.1037

Dell'Acqua F, Lanese I, Polli D (2013) Integration of EO-based vulnerability estimation into EO-based seismic damage assessment: a case study on L'Aquila, Italy, 2009 earthquake. Nat Hazards 68(1):165-180. doi:10.1007/ s11069-012-0490-0

Gamba P, Dell'Acqua F, Trianni G (2007) Rapid damage detection in the Bam area using multitemporal SAR and exploiting ancillary data. IEEE Trans Geosci Remote Sens 45(6):1582-1589. doi:10.1109/TGRS.2006.885392

Guo H, Zhang B, Lei L, Zhang L, Chen Y (2010) Spatial distribution and inducement of collapsed buildings in Yushu earthquake based on remote sensing analysis. Sci China Earth Sci 53(6):794-796. doi:10.1007/ s11430-010-4005-0

Guo H, Liu L, Zhang L et al (2012) Earth observation for earthquake disaster monitoring and assessment. In: D'Amico S (ed) Earthquake research and analysis-statistical studies, observations and planning. INTECH Open Access Publisher, Croatia, pp 293-312

Iribe K, Sato M (2007) Analysis of polarization orientation angle shifts by artificial structures. IEEE Trans Geosci Remote Sens 45(11):3417-3425. doi:10.1109/TGRS.2007.905973

Kimura H, Papathanassiou KP, Hajnsek I (2005) Polarization orientation effects in urban areas on SAR data. In: Proceedings of IGARSS 2005, Seoul, Korea, 25-29 Jul, vol 7, pp 4863-4867. doi:10.1109/IGARSS.2005.1526763

Lee JS, Ainsworth TL (2011) The effect of orientation angle compensation on coherency matrix and polarimetric target decompositions. IEEE Trans Geosci Remote Sens 49(1):53-64. doi:10.1109/TGRS.2010.2048333

Lee JS, Grunes MR (1992) Classification of multi-look polarimetric SAR data based on complex Wishart distribution. In: Proceedings of the national telesystems conference 1992 (NTC-92), Washington DC, United States, 19-20 May, pp 7/21-7/24. doi:10.1109/NTC.1992.267879

Lee JS, Pottier E (2009) Polarimetric radar imaging: from basics to applications. CRC Press, Boca Raton

Lee JS, Grunes MR, Kwok R (1994) Classification of multi-look polarimetric SAR imagery based on complex Wishart distribution. Int J Remote Sens 15(11):2299-2311. doi:10.1080/01431169408954244

Lee JS, Grunes MR, Ainsworth TL, Du L, Schuler DL, Cloude SR (1998) Unsupervised classification using polarimetric decomposition and complex Wishart classifier. In: Proceedings of IGARSS 1998, Seattle, WA, United States, 6-10 Jul, vol 4, pp 2178-2180. doi:10.1109/IGARSS.1998.703778

Lee JS, Grunes MR, Ainsworth TL, Li-Jen D, Schuler DL, Cloude SR (1999) Unsupervised classification using polarimetric decomposition and the complex Wishart classifier. IEEE Trans Geosci Remote Sens 37(5):2249-2258. doi:10.1109/36.789621

Lee JS, Schuler DL, Ainsworth TL (2000) Polarimetric SAR data compensation for terrain azimuth slope variation. IEEE Trans Geosci Remote Sens 38(5):2153-2163. doi:10.1109/36.868874

Lee JS, Ainsworth TL, Wang Y (2014) Generalized polarimetric model-based decompositions using incoherent scattering models. IEEE Trans Geosci Remote Sens 52(5):2474-2491. doi:10.1109/TGRS.2013.2262051

Li XW, Guo HD, Zhang L, Chen X, Liang L (2012) A new approach to collapsed building extraction using RADARSAT-2 polarimetric SAR imagery. IEEE Geosci Remote Sens Lett 9(4):677-681. doi:10.1109/LGRS.2011.2178392

Ma XS, Shen HF, Zhang LP, Yang J, Zhang HY (2015) Adaptive anisotropic diffusion method for polarimetric SAR speckle filtering. IEEE J Sel Topics Appl Earth Observ Remote Sens 8:1041-1050. doi:10.1109/ JSTARS.2014.2328332

Park SE, Yamaguchi Y, Kim D (2013) Polarimetric SAR remote sensing of the 2011 Tohoku earthquake using ALOS/PALSAR. Remote Sens Environ 132:212-220. doi:10.1016/j.rse.2013.01.018 
Sato M, Chen SW, Satake M (2012) Polarimetric SAR analysis of tsunami damage following the March 11, 2011 East Japan Earthquake. Proc IEEE 100(10):2861-2875. doi:10.1109/JPROC.2012.2200649

Shen JC, Xu X, Dong H, Gui R, Song C (2015) Collapsed building extraction from single full polarimetric SAR image after earthquake. Sci Technol Eng 15(14):86-91

Susaki J (2015) Region-based automatic mapping of tsunami-damaged buildings using multi-temporal aerial images. Nat Hazards 76(1):397-420. doi:10.1007/s11069-014-1498-4

Trianni G, Gamba P (2009) Fast damage mapping in case of earthquakes using multitemporal SAR data. J Real Time Image Proc 4(3):195-203. doi:10.1007/s11554-008-0108-7

Watanabe M, Motohka T, Miyagi Y, Yonezawa C, Shimada M (2012) Analysis of urban areas affected by the 2011 off the Pacific Coast of Tohoku earthquake and tsunami with L-band SAR full-polarimetric mode. IEEE Geosci Remote Sens Lett 9(3):472-476. doi:10.1109/LGRS.2011.2182030

Yamaguchi Y (2012) Disaster monitoring by fully polarimetric SAR data acquired with ALOS-PALSAR. Proc IEEE 100(10):2851-2860. doi:10.1109/ JPROC.2012.2195469

Yamaguchi Y, Moriyama T, Ishido M, Yamada H (2005) Four-component scattering model for polarimetric SAR image decomposition. IEEE Trans Geosci Remote Sens 43(8):1699-1706. doi:10.1109/TGRS.2005.852084
Yamaguchi Y, Yajima Y, Yamada H (2006) A four-component decomposition of POLSAR images based on the coherency matrix. IEEE Geosci Remote Sens Lett 3(3):292-296. doi:10.1109/LGRS.2006.869986

Yamaguchi Y, Sato A, Boerner WM et al (2011) Four-component scattering power decomposition with rotation of coherency matrix. IEEE Trans Geosci Remote Sens 49(6):2251-2258. doi:10.1109/TGRS.2010.2099124

Zhai W, Shen HF, Huang CL, Pei WS (2016a) Fusion of polarimetric and texture information for urban building extraction from fully polarimetric SAR imagery. Remote Sens Lett 7(1):31-40. doi:10.1080/21507 04X.2015.1101179

Zhai W, Shen HF, Huang CL, Pei WS (2016b) Building earthquake damage information extraction from a single post-earthquake PoISAR image. Remote Sens 8(3):171. doi:10.3390/rs8030171

Zhang JF, Xie LL, Tao XX (2001) Pattern analysis of remote sensing imagery for some typical earthquake damages. J Nat Disasters 10(2):89-95

Zhao L, Yang J, Li P, Zhang L, Shi L, Lang F (2013) Damage assessment in urban areas using post-earthquake airborne PoISAR imagery. Int J Remote Sens 34(24):8952-8966. doi:10.1080/01431161.2013.860566

\section{Submit your manuscript to a SpringerOpen ${ }^{\circ}$ journal and benefit from:}

- Convenient online submission

- Rigorous peer review

- Immediate publication on acceptance

- Open access: articles freely available online

- High visibility within the field

- Retaining the copyright to your article 